\title{
Single-port endoscopic retroperitoneal adrenalectomy: initial experience
}

\author{
Virgilijus Beiša, Gintaras Simutis, Karolis Lagunavičius, Kęstutis Strupas \\ Clinic of Gastroenterology, Nephrourology and Surgery, Faculty of Medicine, Vilnius University, Lithuania
}

Videosurgery and other miniinvasive techniques 2011; 6 (2): 103-107 DOI: 10.5114/wiitm.2011.23219

\begin{abstract}
Over the last decade, laparoendoscopic adrenalectomy has become the standard of care for adrenal removal. Elimination of a large incision and difficult exposure has decreased postoperative morbidity and length of stay. Single port access (SPA) surgery was developed as an alternative to traditional multi-port laparoscopy, potentially exploiting the already proven benefits of minimally invasive surgery. We applied the SPA technique to adrenalectomy using the posterior retroperitoneal approach. Between January 2010 and July 2010, a 52-year-old female with Conn's adenoma and two females, aged 31 and 39, both diagnosed with pheochromocytoma, underwent single port endoscopic retroperitoneal adrenalectomies. Procedures were performed using two different commercially available specific access devices and conventional laparoscopic equipment. No conversions to open or conventional retroperitoneal approach were necessary. No perioperative or postoperative complications occurred. Operating time ranged from $120 \mathrm{~min}$ to $240 \mathrm{~min}$. All patients were discharged from the hospital 2 days after surgery. The single port access technique has been successfully applied to adrenalectomy as an available alternative to multiport laparoendoscopic adrenalectomy. Exposure, visualization, and dissection are the same as in retroperitoneal endoscopic adrenalectomy. Single port access surgery offers the patient benefits such as faster convalescence, decreased postoperative scarring and better cosmetic effect.
\end{abstract}

Key words: adrenal tumour, adrenalectomy, single port access surgery.

\section{Introduction}

The evolution of surgery today is toward less and less invasiveness [1]. In an effort to maximize the benefits of minimally invasive surgery, a new concept in surgery, natural orifice transluminal endoscopic surgery (NOTES), has emerged [2]. If the NOTES approach is taken to constitute the peak of this trend, one trocar surgery may be viewed as an intermediary development that is gaining increasing support [1]. Single port access (SPA) surgery is a newly emerging surgical technique that decreases postoperative scarring and parietal trauma.

In the past two decades, laparoscopic surgery has replaced open surgery in most abdominal procedures, including adrenalectomies, for which it has become the gold standard for adrenal surgery [3, 4]. Traditional laparoscopic techniques for adrenalectomy usually need a few trocars because retraction of neighbouring visceral organs is necessary to expose the adrenal gland in the retroperitoneum. Single port access adrenalectomy is a safe procedure but requires a lot of experience in laparoscopic adrenalectomy. If any problem occurs during the intervention it is always possible to place additional trocars and convert to multi-port laparoscopy [5]. The anatomical location of the adrenal glands within the upper retroperitoneum has inspired surgeons to adopt the retroperitoneal approach, which is thought to be the most promising 
method to perform single access surgery of the adrenal glands as it offers a direct way to the retroperitoneal organs [6]. Those features have made singleport endoscopic retroperitoneal adrenalectomy a perfect solution for adrenal surgery.

The purpose of this article is to report on our first three cases of adrenalectomy in which the SPA technique was applied and evaluate the feasibility of performing single port endoscopic retroperitoneal adrenalectomies using two different commercially available specific access devices and conventional laparoscopic equipment in the Centre of Abdominal Surgery at Vilnius University Hospital "Santariškių Klinikos".

\section{Case report}

In the Centre of Abdominal Surgery at Vilnius University Hospital "Santariškių Klinikos", during January-June 2010, three single port access adrenalectomies were performed using conventional laparoscopic equipment. The patients were 31 year, 39 year and 52 year old women with body mass index (BMI) $31 \mathrm{~kg} / \mathrm{m}^{2}, 28 \mathrm{~kg} / \mathrm{m}^{2}, 28 \mathrm{~kg} / \mathrm{m}^{2}$ respectively and who complained of high blood pressure.

All patients with adrenal gland lesions were thoroughly examined by an endocrinologist using ultrasound and computed tomography (CT) scans. Blood and urine levels of electrolytes and catecholamines

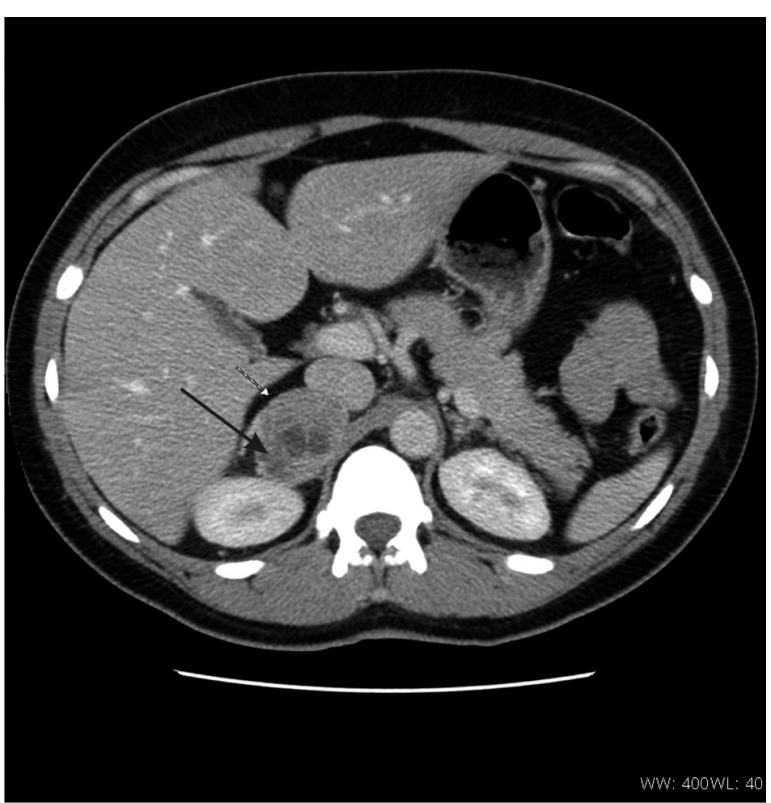

Figure 1. Pheochromocytoma in the right adrenal gland (single-port endoscopic retroperitoneal adrenalectomy: initial experience. Beiša V.) and blood levels of aldosterone and cortisol were evaluated in all patients.

Two patients had increased levels of catecholamines (adrenaline and noradrenaline) in the blood. The third one had increased levels of aldosterone and a reduced level of potassium in the blood. All patients underwent an abdominal CT scan: in the two patients with increased blood levels of catecholamine $45 \mathrm{~mm}$ and $26 \mathrm{~mm}$ pheochromocytoma in the right adrenal gland was observed (Figure 1). The patient with increased aldosterone showed a $10 \mathrm{~mm}$ diameter tumour in the left adrenal gland (Conn's adenoma). Patients with a diagnosed pheochromocytoma received alpha-receptor blockade for 10-14 days preoperatively.

After an explanation of the new method all the patients gave their informed consent. Patient data, operating time, estimated blood loss, perioperative and postoperative complications and outcomes were registered.

\section{Surgical technique}

After induction of general anaesthesia, the patient was placed in the prone jack-knife position. After positioning of the patient palpation of the $12^{\text {th }}$ rib was used to guide the placement of a $2.5 \mathrm{~cm}$ transverse incision just beneath the tip of the rib. Than blunt preparation and opening of the retroperitoneal fascia was performed. After opening of Gerota's fascia the retroperitoneal space was extended with the finger and a special three operating channel SILS ${ }^{T M}$ Port (Covidien AG) (Figure 2) or the TriPort (Olympus Europe Holding GMBH, Hamburg Germany) (Figure 3) was placed. The capnoretroperitoneum is created by a carbon dioxide pressure of $20 \mathrm{mmHg}$.

A conventional $10 \mathrm{~mm}$ scope with a 30-degree viewing angle was used with the SILSTM port. Two $5 \mathrm{~mm}$ cannulas for the introduction of straight conventional laparoscopic instruments $(5 \mathrm{~mm}$ endograsper and $5 \mathrm{~mm}$ ultrasonic dissector) were placed. After exposure and dissection of the adrenal gland the adrenal vein was coagulated and divided with a $5 \mathrm{~mm}$ EnSeal PTC (ERBE Elektromedizin $\mathrm{GmbH}$ ).

The EndoEye (Olympus) $5 \mathrm{~mm}$ rigid scope with a 30-degree viewing angle and two straight conventional $5 \mathrm{~mm}$ laparoscopic endograsper and a $5 \mathrm{~mm}$ ultrasonic dissector were used with the TriPort. The adrenal vein was clipped with medium-large titanium 


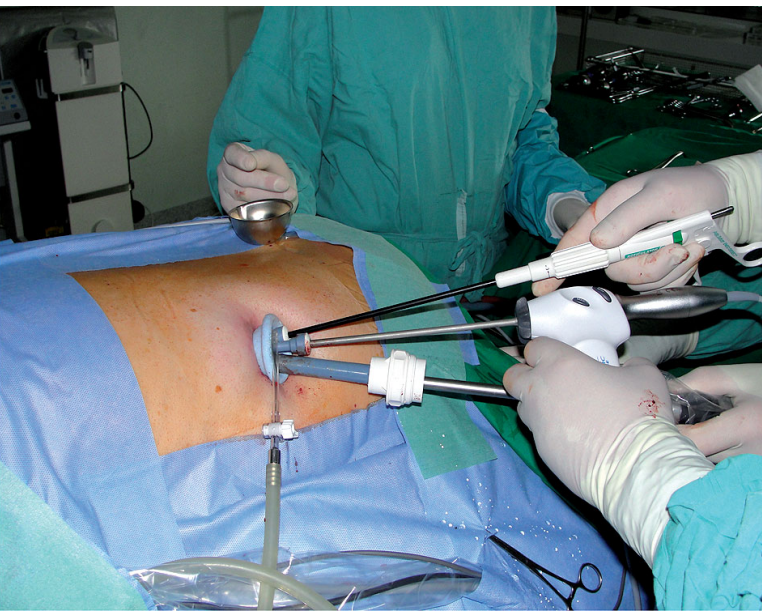

Figure 2. SILSTM port (Covidien AG) (single-port endoscopic retroperitoneal adrenalectomy: initial experience. Beiša V.)

clips and divided using 5-mm conventional laparoscopic scissors.

The specimen was extracted by simultaneous removal of the single port system (Figure 4). No drain was inserted and the incision was closed subcutaneously.

\section{Results}

The results are summarized in Table I. No conversions to the open or conventional retroperitoneal approach was necessary. Mean operating time was $200 \mathrm{~min}$ (range 120-240 min). Blood loss was negligible. No preoperative or postoperative complications occurred. None of the patients received pain medication postoperatively after more than $8 \mathrm{~h}$. Patients were discharged 2 days after adrenalectomy.

\section{Discussion}

Single port surgery is a new minimally invasive approach that represents the next generation in

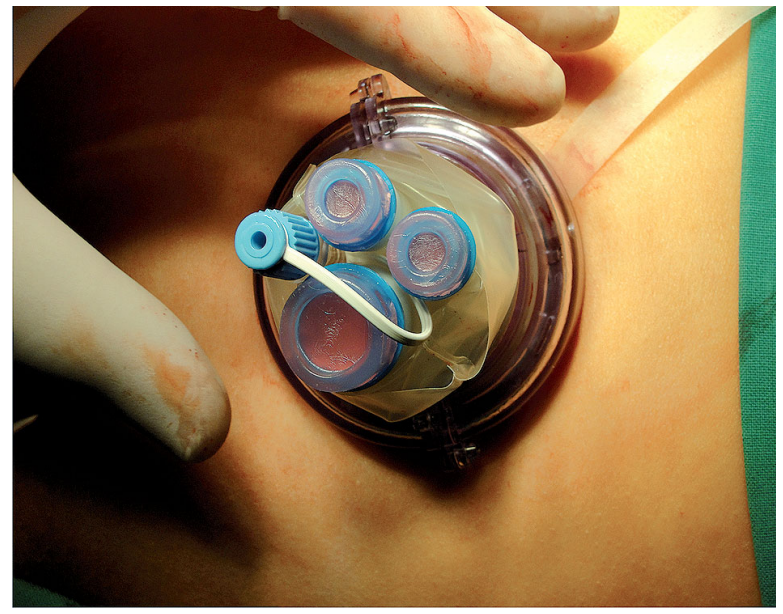

Figure 3. TriPort (Olympus Europe Holding GMBH, Hamburg, Germany) (single-port endoscopic retroperitoneal adrenalectomy: initial experience. Beiša V.)

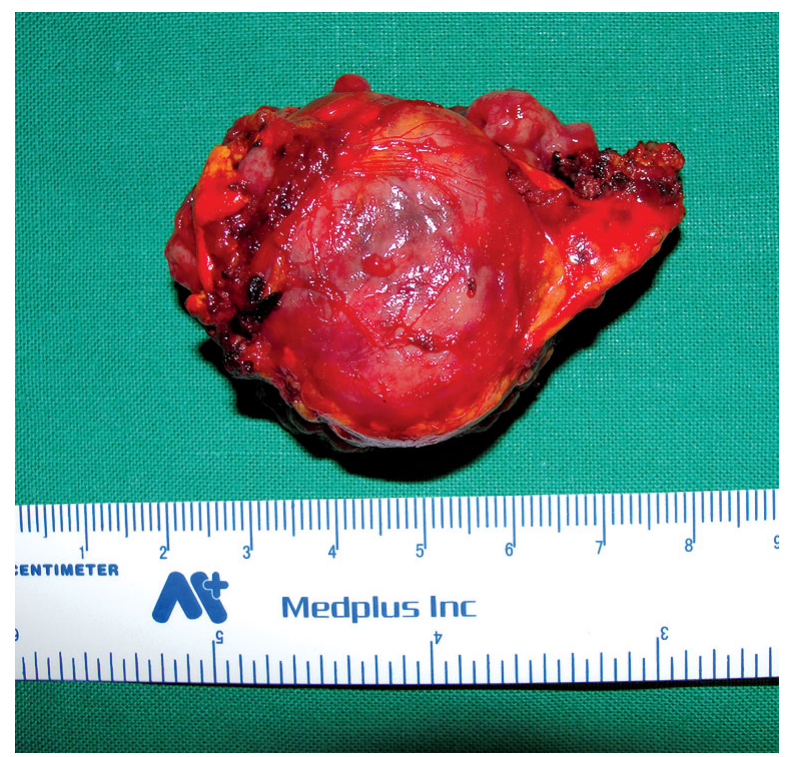

Figure 4. The specimen (single-port endoscopic retroperitoneal adrenalectomy: initial experience. Beiša V.)

Table I. Characteristics of patients undergoing single-port retroperitoneal adrenalectomy

\begin{tabular}{|lcccccccc|}
\hline Patient & Age/sex & $\begin{array}{c}\text { BMI } \\
{\left[\mathrm{kg} / \mathrm{m}^{2}\right]}\end{array}$ & Site & $\begin{array}{c}\text { Size } \\
{[\mathrm{cm}]}\end{array}$ & Diagnosis & Port & $\begin{array}{c}\text { Operative time } \\
{[\mathrm{min}]}\end{array}$ & $\begin{array}{c}\text { Blood loss } \\
{[\mathrm{ml}]}\end{array}$ \\
\hline 1 & $39 / \mathrm{F}$ & 31 & $\mathrm{R}$ & 4.5 & Pheochromocytoma & TriPort & 240 & 20 \\
\hline 2 & $52 / \mathrm{F}$ & 28 & $\mathrm{~L}$ & 1.0 & Conn's adenoma & SILSTM & 240 & 10 \\
\hline 3 & $31 / \mathrm{F}$ & 28 & $\mathrm{R}$ & 2.6 & Pheochromocytoma & SILSTM & 120 & 10 \\
\hline
\end{tabular}


laparoscopic surgery. It uses a single skin incision, often concealed, to perform procedures with minimal scarring and reduced trauma of surgical access. Recent advances in technology and instrumentation coupled with a mastery of laparoscopic surgery have led to single-access procedures being performed in patients with various pathology, including adrenal gland pathology.

Endoscopic adrenalectomy through a single incision using a retroperitoneal approach without gas inflation and trocar port placement was first performed by Kageyama et al. [7]. Later Hirano in 53 patients performed retroperitoneoscopic adrenalectomy using a rectoscope tube of $4 \mathrm{~cm}$ diameter and standard laparoscopic instruments without carbon dioxide insufflation [8]. The authors reported good results, but mentioned the limited possibilities for manipulation of the retroperitoneum via a small incision. Although those interventions were not really laparoscopic, they provided a stepping stone for the evolution of single port surgery.

Castellucci et al. presented the first case of single access laparoscopic transabdominal adrenalectomy using three ports introduced through a $2-\mathrm{cm}$ supraumbilical incision, with successful removal of a left-sided adrenal tumour [9]. Transperitoneal single access adrenalectomy seems to be more difficult with regard to exposure of the adrenal gland but has advantages over the retroperitoneal approach concerning a better working space. However, the transperitoneal procedure has two major disadvantages. First, the distance between the umbilicus and the adrenal gland is longer than the distance between the $12^{\text {th }}$ rib and the adrenal gland, which usually makes the conventional laparoscopic instruments unable to reach the upper pole of the adrenal gland. Second, the standard laparoscopic instrument cannot approach the deeply seated adrenal gland from the umbilicus.

Walz and Alesina developed the single access retroperitoneoscopic adrenalectomy (SARA) method using a two-port single incision technique with a surgeon handling the camera and one instrument simultaneously. Based on their reported five cases, SARA needs a longer procedure time but causes less pain [6].

Specific access devices used in SPA allow multiple instruments to be passed through them at the same time [10]. Several types of these ports are currently commercially available: SILS port (Covidien), LESS TriPort (Olympus), homemade ports, etc. Several case studies published recently presenting the first cases of single access laparoscopic transperitoneal [11, 12] or retroperitoneal $[13,14]$ adrenalectomy using a single multi-lumen port confirmed its safety and feasibility.

While standard trocars can be placed in close proximity within a single small incision, we prefer to use either the TriPort or the SILS port as they provide an additional degree of freedom in a limiting environment. The ability to rotate the port, in some circumstances, may be advantageous with respect to instrument and camera use. This can be particularly useful when using energy devices (ultrasonic shears or bipolar sealing device) and a particular angle is needed. This is not possible with standard trocars as they are fixed at their point of entry.

One of the major problems when performing single port surgery is loss of triangulation, which is a key factor during standard laparoscopic surgery to provide the surgeon with an ergonomic means to perform dissection and suturing. Single port surgery ignores this most basic principle of laparoscopy and can be quite difficult and movements ineffective with straight, non-articulating laparoscopic instruments. In this report, we demonstrate that standard laparoscopic instrumentation is efficient in limited retroperitoneal space and curved instruments are not as useful as in transperitoneal procedures. However, the conventional $30^{\circ}$ scope was the principal cause of difficulty due to the reduced range of instrument motion.

The paucity of published comparative studies makes it difficult to draw conclusions regarding complication rates with SPA adrenalectomy. Future comparative studies should elucidate whether an additional benefit to this technique exists other than a favourable cosmetic result. These studies will probably require more sensitive metrics and longer postoperative follow-up to detect any existing differences.

\section{Conclusions}

Adrenalectomy can be done through a single port access using conventional laparoscopic instruments and continuing technical advances will improve the surgery, probably replacing endoscopic retroperitoneal adrenalectomy.

\section{References}

1. Mutter D, Leroy J, Cahill R, Marescaux J. A simple technical option for single-port cholecystectomy. Surg Innov 2008; 15: 332-222. 
2. Rattner D, Kaloo A. ASGE/SAGES working group on natural orifice transluminal endoscopic surgery. Surg Endosc 2006; 20: 329.

3. Smith CD, Weber CJ, Amerson JR. Laparoscopic adrenalectomy: new gold standard. World I Surg 1999; 23: 389-96.

4. Beiša V, Simutis G, Strupas K. Evaluation of two methods of endoscopic adrenalectomy. Zentralbl Chir 2009; 134: 237-41.

5. Budzyński A, Pędziwiatr M, Matłok M, et al. Preliminary experience with transperitoneal single incision laparoscopic surgery adrenalectomy. Videosurgery and other miniinvasive techniques 2010; 5: 87-92.

6. Walz MK, Alesina PF. Single-access retroperitoneoscopic adrenalectomy (SARA) - one step beyond in endocrine surgery. Langenbecks Arch Surg 2009; 394: 447-50.

7. Kageyama Y, Kihara K, Kobayashi T, et al. Portless endoscopic adrenalectomy via a single minimal incision using a retroperitoneal approach: experience with initial 30 cases. Int I Urol 2004; 11: 693-9.

8. Hirano D, Minei S, Yamaguchi K, et al. Retroperitoneoscopic adrenalectomy for adrenal tumors via a single large port. J Endourol 2005; 19: 788-92.

9. Castellucci SA, Curcillo PG, Ginsberg PC, et al. Single-port-access adrenalectomy. J Endourol 2008; 22: 1573-6.

10. Michalik M, Frask A, Trybull A, et al. Methods of treatment for gallbladder diseases Videosurgery and other miniinvasive techniques 2009; 4: 121-5.

11. Cindolo L, Gidaro S, Tamburro FR, Schips L. Laparoendoscopic single-site left transperitoneal adrenalectomy. Eur Urol 2010; 57: 911-4.

12. Fatih T, Senyurek YG, Terzioglu T, et al. Single-incision laparoscopic left adrenalectomy. Surg Laparosc Endosc Percutan Tech 2010; 20: 291-4.

13. Cywiński J, Kuzdak K, Kołomecki K. One-incision approach (SILS) for retroperitoneal videoscopic adrenalectomy. Videosurgery and other miniinvasive techniques 2010; 5: 70-71.

14. Zhang X, Shi TP, Li HZ, et al. Laparo-endoscopic single site anatomical retroperitoneoscopic adrenalectomy using conventional instruments: initial experience and short-term outcome. J Urol 2010; Dec 15 [Epub ahead of print]. 